\title{
Del resplandor de Nebrija a la Edad Dorada de Cervantes. Humanismo, luz y legitimación histórica: el caso español'
}

\author{
GINÉS TORRES SALINAS \\ Universidad de Granada \\ España \\ ginestorres@ugr.es
}

From the Radiance of Nebrija to the Golden Age of

Cervantes. Humanism, Light and Historic Legitimation:The Spanish Case

(Recibido: 09-IO-20I7; aceptado: $07-07-2018$ )

Resumen. Durante el Renacimiento, desde sus inicios hasta su consolidación, los humanistas utilizaron la contraposición entre luz y oscuridad para legitimar, frente a la medieval, su nueva visión del mundo. En el presente artículo analizaremos el significado concreto con que, en la literatura española de los siglos XVI y XVII, se dota a la luz en dicha contraposición, así como las diferentes modulaciones que adquiere durante el mismo periodo la noción de Edad de Oro.

Palabras clave: luz; oscuridad; Renacimiento; humanistas; Edad de Oro; literatura española.
Abstract. In the Renaissance, from its beginning to its consolidation, humanists used the light/darkness opposition to legitimate their new vision of the world against a medieval one. This paper analyzes the specific meaning of light within that opposition in Spanish literature during the 16th and 17th centuries. Likewise, this paper studies the different acquired modulations for the notion of the Golden Age during the same period.

Keywords: light; darkness; Renaissance; humanists; Golden Age; spanish literature.

\footnotetext{
${ }^{\text {I }}$ Para citar este artículo: Torres Salinas, Ginés,(20r9). Del resplandor de Nebrija a la Edad Dorada de Cervantes. Humanismo, luz y legitimación histórica: el caso español. Alabe 19. [www.revistaalabe.com] 


\section{Una vez más, la edad de la luz}

Planteamos este artículo como la continuación natural de los presupuestos establecidos en un anterior texto, publicado en estas mismas páginas (Torres Salinas, 20I3), donde estudiamos las peculiaridades y el origen concreto que en el Renacimiento adquirían dos series terminológicas, la de la oposición luz/oscuridad y la de la noción de Edad de Oro. Si aquél estaba dedicado a los textos del humanismo italiano, creemos que tenía sentido estudiar su mismo desarrollo en los textos españoles. Con todo, consideramos conveniente resumir, siquiera en esquema, sus conclusiones, pues será de estas de las que partiremos ${ }^{2}$.

Cuando hemos hablado de la existencia de una Edad de la luz, no ha sido con la pretensión de enmarañar todavía más el "círculo vicioso" en que, desde hace ya casi cien años, se han convertido los intentos por ofrecer una definición rotunda e inmutable del concepto de Renacimiento (Cantimori, I97I: 4I5). Eugenio Garin señala que la serie terminológica aparece en en el ámbito de la batalla contra la ignorancia, identificada con la barbarie, de unas universidades que, en el siglo XII, se había entregado a los presupuestos de los lógicos, en detrimento del fervor por los clásicos, y de la humanitas que la enseñanza de éstos pudiera aportar (Garin, ı98га: 54-59). Movimiento que, conviene señalarlo, será la parte visible de un iceberg en cuya base hay algo más sólido, más profundo, "una lucha contra los 'bárbaros', cultural a la vez que política” (p. ı6), esto es, una lucha ideológica. Efectivamente, la aparición de la serie luz/oscuridad en el intento de la burguesía por legitimarse ideológicamente frente al feudalismo sacralizado medieval (Rodríguez, I990: 59-III) en los albores del Renacimiento.

Una legitimación que tendrá lugar a múltiples niveles, de entre los cuales nos interesa detenernos en el historiográfico. En The Renaissance in historical thought (1948), Wallace Ferguson comenta cómo la Chronica florentina de Giovanni Villani, escrita en la primera mitad del siglo XVI, supuso un primer hito en el que cristalizaba una nueva concepción de la historia. En la Edad Media, la historia sería concebida sub specie aternitatis, tomando como referente los seis días de la creación, las cuatro monarquías profetizadas en el libro de Daniel o el mecanismo explicado por Auerbach en Mímesis, según el cual "La meta de la historia de la salvación [que] no es tan solo una esperanza segura para el futuro, sino que se halla cumplida en Dios desde siempre, y prefigurada en cuanto a los hombres de la misma manera que Cristo se halla prefigurado en Adán” (Auerbach, I975: I85). Villani, en cambio comenzaría a ensayar un incipiente estudio independiente sobre la vida económica y política de la Florencia de su tiempo (Ferguson, I948: 6-7). Hans Baron también percibe el cambio en la historiografía florentina. A partir de la Historiarum florentini populi, Libri XII, de Leonardo Bruni, "los fenómenos fundamentales de la vida entre los Estados, previamente subordinada a la teología histórica del Sacrum Imperium, pueden ser considerados de forma más inteligible, dándoles una explicación causal” (Ba-

\footnotetext{
${ }^{2}$ Para una bibliografía y desarrollo más extensos de la cuestión, remitimos a dicho trabajo. Con todo, algunas referencias, las imprescindibles, se repetirán en esta introducción.
} 
ron, I993: 46). Bouwsma, ocupándose ya del siglo XVI, habla de la aparición de un tiempo "secular", distinto del "tiempo sagrado" (2OOI: 77), coincidente "con el surgimiento de las ciudades, en las que el tiempo se medía y valoraba cada vez más para infinidad de usos humanos" (p. 78), por lo que, en consecuencia, la reflexión sobre la historia presentaría un marcado "interés por hacer inteligible la cadena de sucesos" (p. 8I) históricos3.

Como en tantas otras cosas, será Petrarca, padre del humanismo, el primero que se ocupe, al menos si hablamos desde un punto simbólico o canónico, de esta cuestión, como bien explicara en un seminal texto Theodor Mommsen (I942). No es casual, pues, que Ferguson afirme que "Petrarch set the tone for the humanist's secular interpretation of history" (I948: 8); secularización a la cual conduce el hecho de que "desaparecida la Escritura como único sostén del texto" (Rodríguez, 2OOI: 27), "aparecen también los signos literales sustituyendo a las signaturas divinas" (Rodríguez, 20o8: I66). Será en ese contexto donde adquiera particular protagonismo el símbolo luminoso. Recupera Mommsen al respecto un texto del África (IX, 452-457), en concreto, la dedicatoria que dedica al rey de Nápoles, Roberto de Anjou:

[...] a ti, si -como espera y desea mi alma-me sobrevives muchos años, te aguardan quizá tiempos mejores; este sopor de olvido no ha de durar eternamente. Disipadas las tinie-

blas, nuestros nietos caminarán de nuevo en la pura claridad del pasado (en Panofsky, I975: 42-43).

Petrarca hace referencia a un pasado claro y luminoso, identificado en el pensamiento renacentista con la Antigüedad clásica ${ }^{4}$, con su historia y su saber, cuyo mismo esplendor no tardará en ser restaurado, a pesar de que él, inmerso en las tinieblas cuando escribe estas líneas, no confíe mucho en conocer esos tiempos mejores. Desde parecida perspectiva puede entenderse un pasaje de la Apología contra cuiusdam anonymi Galli calumnia, en el que sostiene que "Entre el error brillaban hombres de genio, y no menos aguda era su vista, aunque estuvieran rodeados de oscuridad y densa niebla” (en Mommsen, I942: 225)5. Los ejemplos, como ya señalamos en su momento, son abundantes en la literatura italiana, pero no privativos de la misma. Será nuestro propósito en estas

\footnotetext{
${ }^{3}$ Cfr. el magnífico análisis que, al hilo de textos como el La Celestina o el Lazarillo. Juan Carlos Rodríguez realiza de la contraposición entre la noción feudal del tiempo y la nueva noción del tiempo burgués, entendido éste como mercancía (2OOI: I35-I49).

4 El propio Petrarca se preguntará “¿Qué otra cosa es la historia, sino el elogio de Roma?”: Quid est enim aliud omnis historia quam Romana laus? (en Mommsen, I942: 237). Cfr. al respecto, Juan Carlos Rodríguez, quien ha explicado (I990: I43-I 46) cómo esta vuelta a la Antigüedad se debe a que "la ideología burguesa desde su primera fase "humanista italiana" utilizó una especial imagen de "lo griego" (o del mundo heleno-romano en general) forjada en las necesidades de su lucha contra el escolasticismo feudal" (p. I43). Con todo, conviene señalar que no siempre en Petrarca nos encontraremos el gesto puro renacentista, situado como está en la bisagra entre dos mundos. Así se explica por ejemplo un pasaje del De ignorantia en que Petrarca lamenta que Cicerón muriera apenas cuarenta años antes del nacimiento de Cristo: “ ¡Cuánto he compadecido su suerte, al leer sus obras! ¡Lamento tanto en mi fuero interno que ese hombre no haya conocido al verdadero Dios! La muerte cerró sus ojos pocos años antes del nacimiento de Cristo. ¡Cuán próximos estaban, ay, el fin de la tenebrosa noche del error y el comienzo de la era de la verdad! Era inminente el alba de la luz verdadera y el sol de la justicia" (Petrarca, I978: I82). La serie luz/oscuridad se lee desde la venida al mundo de Cristo, centro de la historia medieval (Mommsen, 1942: 227, Ferguson, I948: 8), que debería interpretarse según un "desarrollo continuo como un progreso ininterrumpido desde las tinieblas paganas hasta la luz de Cristo" (Panofsky, 1975: 42).
}

5 Elucebant tamen inter errores ingenia, neque ideo minus uiuaces erant oculi quamuis tenebris et densa caligine circumsepti. 
páginas abordar el modo en que la literatura española también se siente inmersa dentro de esta Edad de luz.

\section{Un resplandor antes nunca visto: lengua, luz e imperio}

En la península, el recorrido de la serie luz/oscuridad/tinieblas conocerá cierto desfase cronológico, debido al tardío inicio del Renacimiento español, simbólicamente establecito en I48I, con las Introductiones latinae de Antonio de Nebrija (Rico, I996: 9) . El Marqués de Santillana es ejemplo de tal desfase. En el Proemio e carta al Condestable Don Pedro de Portugal (López de Mendoza, 2002: 50I-512) confiesa que ha leído a Petrarca y a Bocaccio, adalides del nuevo tiempo renacentista. Sin embargo, y lo demostrará al cabo el intento fallido de sus sonetos, sigue siendo un hombre profundamente medieval. Se comprueba cuando, en un pasaje del texto referido a la dignidad de la poesía, "de mayor perfecçión e más auctoridad que la soluta prosa” (p. 503), escribe:

Afírmalo Casiodoro en el libro De varias causas, diziendo: todo resplendor de eloquençia e todo modo o manera de poesía o poetal locuçion e fabla, toda variedat de honesto fablar hovo e houieron començamiento de las Diuinas Escripturas (p. 504).

La luz, el resplandor de la elocuencia, de la sabiduría, que en Petrarca y su descendencia humanista miraban hacia la Antigüedad clásica y el modelo ciceroniano, son leídos por el Marqués desde una óptica sacralizada que explica la naturaleza de dichos brillos retóricos por su origen en "las Diuinas Escripturas". No deja de ser significativo que, a su muerte, Pero Díaz de Toledo escriba del Marqués en elogiosos términos, de una luminosidad, si no cercana a los anhelos humanistas, al menos sí ausente de la mirada sacralizada del Marqués, en su deseo de que "la olvidança, madrastra de la memoria, é discurso de tiempos, non trayan en tiniebra la lumbre é clandor de las grandes virtudes deste caballero" (I892: 248).

Hacia I48I, el protonotario Juan de Lucena escribe una Carta exhortatoria a las letras (I892: 209-2I7). Su defensa del estudio letrado pone sobre la mesa, al final del texto, la necesidad por recuperar un latín deformado y olvidado en el momento de redactar la Carta. La propia Isabel la Católica sirve de ejemplo ${ }^{z}$ a una empresa intelectual en la cual "La muy clara ninfa Carmenta letras latinas nos dió; perdidas en nuestra Castilla, esta diua serena las anda buscando. Si al su resplandor miramos todos por ellas, non puede ser que non las hallemos” (p. 2I6). En Juan de Lucena, la necesidad de recuperar la lengua

\footnotetext{
${ }^{6}$ La cuestión, lógicamente, es muchísimo más compleja, pues los primeros indicios de modernidad en las letras castellanas se pueden remontar a pleno siglo XV, especialmente a partir del contacto peninsular con los humanistas italianos, en las dos direcciones del intercambio. Cfr. Soria Ortega (i956), Gómez Moreno (I994), Ynduráin (I994), Maravall (I996) o Gargano (20I2).

7 Inolvidable aquel malicioso "Jugaba el rey, éramos todos tahúres; studia la Reina, somos agora studiantes” (Lucena, I892: 216).
} 
latina se une ya estrechamente a un referente, además de pagano y desacralizado, luminoso y resplandeciente, como la edad nueva que la ninfa profetizará.

Es Nebrija quien asimila del todo y aquilata una lección humanista que tuvo oportunidad de forjarse en los ambientes italianos del Real Colegio de España de Bolonia. Es emblemática la declaración al inicio de su Vocabulario Español Latino, de I495:

en edad de diez y nueve años io fue a Italia, no por la causa que otros van, o para ganar rentas de iglesia, o para traer fórmulas de Derecho civil y canónico, o para trocar mercaderías, mas para que por la ley de la tornada, después de luengo tiempo restituiesse en la possessión de su tierra perdida los autores del latín, que estavan ia, muchos siglos avía, desterrados de España (I989: a. ii. v.).

La cercanía al tono del humanismo italiano es ya manifiesta. Su programa intelectual buscará la restitución de los estudios “desterrados de España”, latinos en el caso del Vocabulario. En el prólogo a la Gramática, de I492, declara a la reina: “I así, después que io deliberé, con gran peligro de aquella opinión que muchos de mí tienen, sacar la novedad desta mi obra de la sombra y tinieblas escolásticas a la luz de vuestra corte" (I98I: IO2). Nebrija reproduce el clásico ataque humanista contra la ignorancia ${ }^{8}$, en la contraposición entre la bárbara oscuridad escolástica y la luz de la corte de la "muy esclarecida reina" Isabel la Católica, a quien va dirigida una obra que se define desde una "conclusión muy cierta: que siempre la lengua fue compañera del Imperio" (p. 97). La luz del florecimiento intelectual se pone al servicio de un movimiento de legitimación política, recuperando "la metáfora de la translatio imperï junto a su acólito, la translatio studiu"

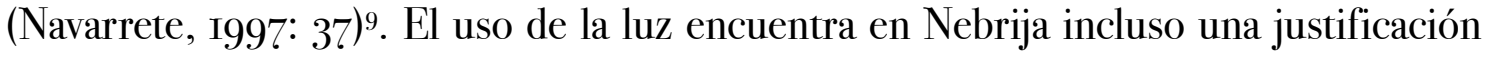
teórico-lingüística. En el capítulo que trata del orden de las partes de la oración escribe:

Entre algunas partes de la oración ai cierta orden casi natural y mui conforme a la razón, en la cual las cosas que por naturaleza son primeras o de maior dignidad, se an de anteponer a las siguientes y menos dignas [...] y así diremos por conseguiente: el cielo y la tierra, el día y la noche, la luz y las tiniebras, y no por el contrario, la tierra y el cielo, la noche y el día, las tiniebras y la luz (I98I: 205).

El lugar común, en apariencia atemporal o ahistórico, adquiere en los estudios gramaticales de Nebrija una dimensión concreta que lo emparenta con el contexto de la comunidad humanista europea: ya no se trata, como sucedía al Marqués de Santillana, de acudir al Casiodoro que fija el canon del brillo retórico en las Escrituras, sino de traer a España la luz pura de la lengua y los saberes eruditos que honrarán a un imperio con el que irá de la mano en lo que a resplandores se refiere.

\footnotetext{
${ }^{8}$ Cfr. Rico (1978).

${ }^{9}$ Cfr. en realidad, pp. 29-50 y Maravall (1986, 216-220).
} 
Así se abre el camino inmediato a textos como el Arte de poesía de Juan del Encina. Escrito en I496, se trata de un texto consciente del origen italiano del vigor que conocen los poetas españoles: “Assí que concluyamos luego el trovar aver cobrado sus fuerças en Italia, y de allí esparzídolas por nuestra España, adonde creo que ya florece más que en otra ninguna parte" (Encina, I996: I4). Al hilo de la reflexión sobre la necesidad de un cierto ingenio por parte del poeta, Encina reproduce la oposición, ya extendida por buena parte del espacio cultural europeo, entre estudiosos y bárbaros, a través del paradigma luminoso:

Assí que aqueste nuestro poeta que establecemos instituyr, en lo primero venga dotado de buen ingenio. Y porque creo que, para los medianamente enseñados, está la verdad más clara que la luz; si oviere algunos tan bárbaros que persistan en su pertinacia, dexados como incurables, nuestra exortación se enderece a los mancebos estudiosos, cuyas orejas las dulces musas tienen conciliadas (pp. I6-I7).

Se va consolidando así la imagen de una época luminosa, portadora de un saber -una vida- que, tras haberse perdido en las tinieblas bárbaras del pasado inmediato, resurge en la obra y la actitud tanto de los principales humanistas como de lo que Rico llamó "la tropa de maestros humildes, grises que - a jornal de los municipios o de los señores, en la universidad o en las casas eclesiásticas- hizo seguramente más que cualquier otra facción por la siembra del Renacimiento en España" (I978: IOO-IOI).

Ambrosio de Morales representa a la perfección la continuidad del legado humanista. Profesor en la Universidad de Salamanca, sucesor de Florián de Ocampo como cronista de Castilla, autor de unas Antigüedades de las ciudades de España con las que da cauce a su profundo interés por la arqueología, en I543 escribe un Discurso sobre la lengua castellana, plenamente inscrito en la senda del humanismo:

La historia romana y mucho de la antigüedad latina y griega hablan ya hermosamente y con propiedad y limpieza el castellano en los libros de Pedro Mexía, de cuya mucha doctrina y gracia en el decir harto sería bueno que yo bien gustasse sin que me atreva a alabarla como meresce. Ya las cosas antiguas de España, sacadas de las tinieblas y escuridad en que estavan, tienen mucha luz, no solamente con la diligencia increíble del Maestro Florian de Ocampo, sino también con su copioso y agudo género de decir, donde la abundancia differenciada con una sutileza cuerda y muy medida, atavía prudentemente el lenguaje (Morales, I95': 58-59).

El pasaje nos presenta ya una primera conciencia histórica humanista. No se piensa en un futuro proyecto de restauración del pasado, sino que da cuentas de su ejecución. El gesto casi arqueológico, al que él mismo se adscribirá, tiene su correlato en la imagen luminosa: los vestigios de la Antigüedad permanecieron en las tinieblas del desconoci- 
miento hasta que Florián de Ocampo les ha otorgado la "mucha luz" de que disfrutan en el momento en que Morales escribe estas líneas.

Poco después, se ocupa de la comparación entre la lengua literaria italiana y la española, a partir de la figura central de Garcilaso: "Y no fuera mucha gloria la de nuestra lengua y su poesía en imitar el verso italiano, si no mejorara tanto en este género Garcilasso de la Vega, luz muy esclarecida de nuestra nación” (p. 6o). Garcilaso, que, desde muy poco después de su muerte, es ya es norma cierta de la poesía, se ha convertido en luz de la nación. Si Nebrija sacó a la lengua española de las oscuridades escolásticas para hacerla, a la vez, luz y compañera del imperio, Garcilaso, gracias a sus poemas, ha dado lugar a la forma más perfecta de la lengua y, por tanto, según esta lógica que rige los primeros pasos del humanismo, en la forma más perfecta de la luz nacional, todo ello en el espacio de cruce en que convergen identidad nacional y lengua literaria.

La consolidación definitiva de Garcilaso como "príncipe de esta poesía en nuestra lengua" (Herrera, 200I: 278) vino con las Anotaciones a la poesía de Garcilaso, publicadas por Fernando de Herrera en I580. Las Anotaciones, verdadera enciclopedia de la poética renacentista, afianzan también en ciertos pasajes la idea de un Garcilaso príncipe luminoso ${ }^{\mathrm{IO}}$ de la poesía española. Es el caso del prólogo que Francisco de Medina, humanista sevillano del círculo de Juan de Mal Lara, escribe a la obra. Parte de la idea nebrisense, ya glosada, de la lengua compañera del imperio: "Siempre fue natural pretensión de las gentes virtuosas procurar estender no menos el uso de sus lenguas que los términos de sus imperios" (Medina, 2OOI: I87); "i veremos estenderse la magestad del lenguaje español, adornada de nueva i admirable pompa, hasta las últimas provincias donde vitoriosamente penetraron las banderas de nuestros exércitos” (p. 203). Matiza, sin embargo, que, frente al optimismo de Nebrija, la lengua en España está todavía "tan descompuesta i mal parada, como si ella fuesse tan fea que no mereciesse más precioso ornamento o nosotros tan bárbaros que no supiésemos vestilla del que merece" (p. I89). Los motivos de tal rudeza hay que encontrarlos en la historia reciente: "no es gran maravilla que aviendo tan poco que sacudimos de nuestras cervices el yugo con que los bárbaros tenían opresa la España", "los buenos espíritus" hayan "atendido con más fervor a recobrar la libertad de la patria que a los estudios de ciencias liberales, que nacen i se mantienen con el ocio" (p. 194), por lo que será comprensible que "no esté desbastada de todo punto la rudeza de nuestra lengua" (p. 194).

El influjo de estos bárbaros fue tal que incluso aquellos que

se preciaron de escrevir i hablar bien, dieron consigo en no pequeños defetos, como quien en la oscuridad de aquellos siglos andava a ciegas sin luz de l’arte, que es más guía cierta que la naturaleza. Espessáronse tanto las tinieblas d'esta inorancia que aun no les dexaron conocer bien las vozes de nuestra pronunciación ni las letras con que se figuran (p. I94).

${ }^{\text {Io }}$ Cfr. Keniston (I922: 4OI-434). 
Se reproduce una vez más la contraposición entre luz y tinieblas, barbarie y estudio. Para Medina, Garcilaso, "príncipe de los poetas castellanos" (p. r97), supo y pudo escapar de las tinieblas de la ignorancia, como deuestran unas obras donde "el arreo de toda la oración está retocado de lumbres i matizes que desprenden un resplandor antes nunca visto" (p. I97). Fernando de Herrera, autor del libro que Medina está prologando, no podía quedar fuera de sus elogios. Con su comentario a la obra de Garcilaso o con su Relación de la guerra de Cipro i de la vitoria naval del señor don Iuan de Austria, entre "algunas de muchas obras que tiene compuestas en todo género de versos" (p. 202), el poeta sevillano contribuirá “a descubrir más clara la gran belleza i esplendor de nuestra lengua, i todos encendidos en sus amores la sacaremos [...] del poder de los bárbaros” (p. 202). Garcilaso y Herrera son, para Medina, los dos mejores ejemplos de una luz, la de la lengua literaria, pareja al proyecto imperial que, desde Nebrija, la piensa como instrumento de expansión nacional.

Por eso se entiende que Herrera insista sobre la cuestión luminosa en las Anotaciones, si bien rebajando la carga patriótica para intensificar el programa erudito. Su propia empresa comentarista se asienta en su intención de "abrir el camino a los que sucedieren, para que no se pierda la poesía española en la oscuridad de la inorancia”, de modo que, aunque "No soy tan temerario que espere ver mucho en tanta niebla [...] oso prometer que será de algún provecho a los que están agenos de la inteligencia d'esta arte” (Herrera, 2OOI: p. 264). Son dos los pasajes de las Anotaciones en que Herrera se ocupa de la naturaleza concreta de esa ignorancia. En ambas aparece bajo la marca de la oscuridad. El primero de ellos hace referencia al caso italiano, el cual, después de la "felice i gloriosa edad de Augusto" sufre a la "bárbara pero belicosa nación de los godos”, "destruyendo los sagrados despojos de la venerada antigüedad". Como consecuencia de esta pérdida, señala Herrera, “fue poco a poco oscureciendo i desvaneciéndose en la sombra de la inorancia la eloquencia i la poesía con las demás artes y ciencias” (p. 204). El segundo pasaje se ocupa del caso español, con balance parecido al de Francisco de Medina. La pugna con los reinos musulmanes trajo consigo la imposibilidad de los españoles para dedicarse al estudio con toda la aplicación y dedicación que éste merecía, de modo que:

quedaron por la mayor parte agenos de su noticia i apena pueden difícilmente ilustrar las tinieblas de la oscuridad en que se hallaron por tan largo espacio de años. Mas ya que an entrado en España las buenas letras con el Imperio i an sacudido los nuestros el yugo de la inorancia, aunque la poesía no es tan generalmente onrada i favorecida como en Italia, algunos la siguen con tanta destreza i felicidad que pueden poner justamente invidia i temor a los mesmos autores d'ella, [Uno de ellos es el Marqués de Santillana, cuyos sonetos son] dinos de veneración por la grandeza del que los hizo i por la luz que tuvieron en la sombra i confusión de aquel tiempo (p. 278). 
El final no carece de interés. Herrera identifica, sin explicitarlo así, el pasado justamente anterior con la oscuridad de la ignorancia, motivada, lo hemos visto, por las circunstancias históricas. De ahíla imagen que del Marqués de Santillana ofrece Herrera. Como señalamos anteriormente, Santillana no participa de los presupuestos luminosos que los humanistas dan a la serie terminológica, pero Herrera, sin embargo, le dota de los mismos, en virtud de su dedicación al soneto, situándolo así como precursor de Garcilaso, Boscán o Gutierre de Cetina, esto es, como precursor de su propia práctica poética.

Casi una década después de la publicación de las Anotaciones, Pedro Simón Abril, gramático y pedagogo, escribe en I589 unos Apuntamientos de cómo se deben reformar las doctrinas y la manera de enseñarlas. En el prólogo, dirigido a Felipe II, leemos:

Y pues vuestra majestad, por merced particular que Dios ha querido hacernos, tiene la suprema potestad temporal en la mayor parte del mundo, los que desean ver las buenas letras quitadas del barbarismo en que hoy están puestas, y reducidas a su antigua luz y perfición para mayor bien de la república, de necesidad han de acudir a vuestra majestad a dalle aviso de esto, como a quien solo en la tierra tiene poder y autoridad para poner remedio en ello (Simón Abril, 2007: 22I).

Bajo el polvo de la retórica católica e imperial, de omnipotencia regia que se comienza a acumular sobre el texto, encontramos una reproducción fiel del esquema humanista luz/oscuridad. Las "buenas letras" deberán abandonar el yugo del oscuro "barbarismo", pues la restauración de su luz no será simplemente una cuestión de escritorio, sino una necesidad de toda la república.

A pesar de que todavía en i63i Juan de Robles, en la Primera parte del culto sevillano, escriba que el ejercicio de la pluma permitió que escritores como Fray Antonio de Guevara o Pedro Mexía diesen "alegres principios a la elocuencia con sus obras en prosa, y Garcilaso con las suyas en verso, con cuyo ejemplo y la comodidad de la paz salieron tras ellos clarísimos soles" (Robles, 2007: 36o), según avanzan el siglo XVI y el reinado de Felipe II, la serie terminológica comienza a fosilizarse. Esta luz que los estudios y las letras traen desde una Antigüedad que venía a superar las tinieblas de la ignorancia medieval se convierte en un lugar común que se verá orillado, vaciado del significado que los humanistas le otorgan y del que hemos ofrecido algunos ejemplos.

Un primer vaciado vendrá de la mano de la llamada "cultura del barroco" (Maravall, r980), que con Trento y la Contrarreforma como hitos históricos, abordaría la "resacralización" de una sociedad, de una cultura en la cual "los signos no son signos en sí, sino que son signaturas que llevan dentro la sustancia divina" (Rodríguez, 2008: I66). Un muy buen ejemplo lo encontramos en la Rhetórica en lengua Castellana, que el jerónimo Miguel de Salinas escribe en I54I. La obra está dedicada a Felipe II con un texto en forma de epístola, en el cual podemos conocer el motivo por el que Salinas la ha compuesto: 
Para que del todo no se pierdan las sciencias paresce ser justo que de nuevo salgan a la luz muchos libros, con tal presupuesto que sean todos buenos y cathólicos. Si esto no fuera y de muchos años se uvieran cansado los hombres de escrevir, ¿qué sería de nosotros?, ¿qué luz tuviéramos ni qué camino lleváramos en este valle? (Salinas, 2007: I24).

La comparación con el prólogo a los Apuntamientos muestra el cambio que se ha efectuado en la concepción de la serie terminológica. La cercanía al clima del humanismo, a la lección de Nebrija o de Medina, que encontrábamos en el texto de Abril, no aparece ya en el de Salinas, siendo incluso anterior a éste. Los dos textos están dirigidos a Felipe II, pero su lógica ya es distinta. En los prolegómenos de Trento, la luz de Salinas sufre una mutación con respecto a sus antecedentes. La luz que deberían traer los libros no remite ya a una Antigüedad clásica a la que miraba la burguesía, sino a una estricta y pura catolicidad. Igual que en la Edad Media, la luz se entiende desde una palabra que no es en absoluto casual. Cuando Salinas habla de "este valle" está recurriendo al imaginario cristiano del valle de lágrimas, del tránsito del hombre por el mundo, en busca, o a la espera, de alcanzar el mundo verdadero que llega al final de dicho tránsito, basta con pensar en el prólogo a los Milagros de Nuestra Señora, de Berceo.

No es sólo, repetimos, que los libros y las ciencias deban ser "buenos y cathólicos". La clave del giro que está sufriendo la simbología luminosa reside en el nuevo papel que ésta desempeña. La luz sirve de guía en un camino muy concreto, muy determinado, aquel que cruza el valle mundano de la vida, y que no tiene más valor que el del destino último que se pretende alcanzar al final de la misma. Frente al que tenía en Petrarca o en Nebrija, la luz ya no apunta a la Antigüedad, según el programa de los studia humanitatis, para conseguir así dar lugar a un periodo histórico nuevo. Ahora será una suerte de foco o lámpara atemporal, encendida por "muchos libros” entendidos como guías del hombre por un recorrido que, situado fuera de la historia, sería siempre el mismo. Ya no el que devuelve a la luz sabiduría clásica olvidada largo tiempo y en la que encontrar un nuevo modelo de comportamiento moral -pensemos en el ejemplo de los cancilleres florentinos que tan bien estudió Garin a partir de la figura de Salutati (I98Ib)-, sino el del hombre por el lachrimarum valle de lo que no tiene valor en sí mismo, sino en espera de la otra vida ${ }^{\mathrm{II}}$.

Un segundo vaciado se explica a partir de determinados cambios en la concepción de la lengua, en la reflexión sobre su sentido. Para entenderlo debemos comprender que el estado de los estudios humanistas sufrió un cierto cambio en su médula, acaso inevitable, según avanzaba el tiempo. Francisco Rico habla de un humanismo ya crepuscular, cuyo éxito trajo a su vez, su propia condena, ya que, una vez alcanzado su objetivo, "la filología clásica deja de ser el motor principal de la cultura y se convierte para siempre en una técnica auxiliar de la historia y de la crítica literaria, sin influir salvo en una parva medida en el rumbo de otros saberes" (Rico, I993: 94). El proyecto inicial de Nebrija,

${ }^{\text {II }}$ Cfr. nota 2. 
basado en la necesidad de volver la mirada hacia el pasado latino para restituir un saber hurtado a la luz por la bárbara sombra del lenguaje escolástico, derivará en un interés por la propia lengua vulgar, su desarrollo, su grado de perfección. La atención se dirige ahora, no tanto a lo que hay que recuperar en su pureza originaria, sino a lo que está por venir, al desarrollo de la lengua por sí misma (García Dini, 2007: 52-54).

Así entendemos un poema que en I65I Gerónimo de San Josef intercala en su Genio de la Historia:

Renacerán muchas cosas / de las que murieron ya, / i morirán las que viven / cediendo a la lei fatal. / Los vocablos que oi más brillan, / toscos mañana serán; / si así lo quisiere el uso, / que es el dueño del hablar. / Como la selva cada año / viste follage galán / mudándose nuevo adorno / que después ha de mudar. / Así del lenguaje antiguo / la ya envegecida edad / con belleza de vocablos / siempre reflorecerá. / Y al modo que el joven tierno / lozanea su beldad, / el nuevo estilo, que oi nace, / triunfa, i reina sin igual (San Josef, 2007: $3^{82}$ ).

Un concepto decisivo en la lingüística, el de uso, cambia la dirección de las reflexiones lingüísticas sobre la serie terminológica. Se mantiene, es cierto, su relación con la historia; sin embargo, en Petrarca o Nebrija la búsqueda de la luz, del esplendor, se hacía con el objetivo de rescatar de la ignorancia los estudios, sin pensar nunca en una posible caída posterior, en un regreso de la bárbara oscuridad. En cambio, San Josef, en sus versos, propone una idea del renacer que se entiende como algo cíclico y sustancial a la naturaleza de los propios vocablos. La luz no es un absoluto que alcanzar, sino algo que en un momento determinado se agotará, pues en el ciclo que propone "los vocablos que hoy más brillan / toscos mañana serán”. Lo que en Petrarca, en Nebrija, en Medina, era un programa intelectual y vital que encontró cifra predilecta en el símbolo de la luz, aquí se ve reducido a un trámite al que el lenguaje, antes o después, será sometido. La luz de la lengua era, a finales del siglo XV y durante el XVI, una herramienta central en el combate intelectual contra la oscuridad, las tinieblas, condensadoras en su imagen de un mundo, el medieval, que se trataba de superar; ya en el XVII, en cambio, está más cerca del lugar común, del significado vacío, que del anhelo humanista por legitimarse a partir de la luminosa Antigüedad clásica. 


\section{Edad de Oro / Edad de Hierro: de Garcilaso a Gracián}

Fenómeno paralelo encontramos en el trazado que la idea de la existencia de un Siglo de Oro tiene en España ${ }^{12}$. Se trata de una noción, es bien conocido, que partiría de la existencia, en un pasado tan mítico como remoto, de "una edad de oro en la que los hombres vivirían en armonía, unidos por ideales comunes, o, cuando menos, respetando los ideales ajenos" (Blecua, 2006: 33), cuyo anhelo será utilizado con cierta recurrencia a lo largo de la historia, indica Levin, para explicitar un cierto cansancio de la realidad (I972: 8). Un anhelo que se manifestará en dos posibles direcciones, muchas veces incardinadas, una que "va hacia un pasado quimérico, la edad dorada o de Saturno; otra hacia el presente, con aspiración a hallar realmente algo que pertenezca a esa pura naturaleza” (Castro, 2009: I69-I7O). No es de extrañar así que el panorama histórico de la bisagra entre el mundo medieval y el moderno encuentre en esta imagen, ya desde lo que Gombrich llamó "el mito de los Médicis" (I984: 69), una manera de explicitar la conciencia de vivir en un tiempo nuevo, luminoso frente a la barbarie medieval, gracias a la aparición de una serie de figuras prominentes, los gobernantes entre ellas. Lo comprobamos en algunos pasajes de nuestras letras.

Cervantes, en La Galatea, pone en boca de Calíope un elogio al escritor Marco Antonio de la Vega, que emparenta con los elogios a Garcilaso estudiados en el epígrafe anterior:

La sabia frente del laurel honroso / adornada veréis de aquel que ha sido / en todas sciencias y artes tan famoso / que es ya por todo el orbe conoscido. / Edad dorada, siglo venturoso, / que gozar de tal hombre has merescido: / ¿cuál siglo, cuál edad ahora te llega, / si en ti está Marco Antonio de la Vega? (Cervantes, I993: 337).

En los Coloquios de Palatino y Pinciano de Juan de Arce de Otálora, compuestos a mitad del siglo XVI, se recuerda cierta costumbre de la Antigüedad, según la cual, en los estudios públicos "como lo hacían los romanos", se pagaba "del erario público a los maestros", ya que "Si en este tiempo hobiera los maestros públicos y salariados que había en los siglos pasados, poca fuera la ventaja. Pero ya pasó esa edad dorada” (Arce de Otálora, r995: 362 ).

Igual de interesantes son otros ejemplos que se aplican al espacio de la política. Hernán López de Yanguas escribe en I529 una Farsa de la concordia, para celebrar la firma de la Paz de Cambrai entre Francisco I y Carlos V. Ya en ella se lee: "J. ¡Oh, qué edad, / qué tiempo de caridad, / es llegado a nuestra España! / T. Cada cual en su cabaña / terná gran seguridad. / M. Ya es tornada / otra vez la edad dorada, / Saturno ya resucita, / la plata y cobre se quita, / la de hierro es acabada.” (López de Yanguas, I967: II7). La

\footnotetext{
I2 Para la cuestión de la relación de la luz y la historiografía con la noción de Siglo de Oro, así como sus antecedentes históricos en Hesiodo, Ovidio, Virgilio, etc. cfr. la primera parte de este trabajo (Torres Salinas, 2OI3).
} 
firma del armisticio, la presencia de Carlos V, auguran la llegada de una brillante edad de oro que traerá seguridad al pueblo, todo ello, además, con la indisimulada referencia mitológica a Saturno, de tanto sabor humanista.

Bienvenido Morros (2007: 282) encuentra una alusión al término en la segunda égloga de Garcilaso. El poeta toledano celebra así el nacimiento, en I5O7, del tercer duque de Alba, Fernando Álvarez de Toledo: “Un infante se vía ya nacido, / tal cual jamás salido d'otro parto / del primer siglo al cuarto vio la luna; en la pequeña cuna se leía / un nombre que decía: “Don Fernando" (Garcilaso, 2007: 282; vv. I279-I283). La noción de Edad de Oro no aparece de manera explícita, lo que lleva a Morros a ensayar dos posibles interpretaciones del pasaje: "“desde la Creación (del primer siglo) al nacimiento de Cristo (al cuarto)...', aunque no cabe descartar la interpretación 'desde la edad de oro (del primer siglo) a la de hierro (al cuarto)"' (Morros, 2007: 282); en otras palabras, la interpretación medieval o la renacentista. Optamos aquí por esta segunda, por dos razones. En primer lugar, porque la recuperación renacentista del mundo clásico encaja mejor con el pasaje que la escatología cristiana, indidable reminiscencia virgiliana mediante. En segundo lugar, porque para la época de redacción de la égloga, hacia I533-I534 (Lapesa, I985: I87), Garcilaso habría leído (Keniston, I922: г24; Altolaguirre, I989: I24-I29) la traducción de El Cortesano ( $55^{28}$ ) que su amigo Juan Boscán dio a la imprenta en I534. En su cuarto libro, Otavián Fregoso, duque de Génova, habla de "la buena manera de gobernar y reinar como es razón, la cual sola bastaría a hacer a los hombres bienaventurados, y restituir otra vez al mundo aquella edad de oro, que fue, según se escribe, en el tiempo en que reinó Saturno" (Castiglione, 2009: 395). La Edad de Oro se engarza así con el deseo de aparición de una figura pública que traiga a sus gobernados la paz arcádida que las caracterizaciones clásicas otorgaban a dicha aetas.

De modo que, aunque Garcilaso no la desarrolla en exceso, la noción de la Edad de Oro, aparece tintada de una considerable dimensión política, más explícita, aunque igual en su raíz, que la que encontrábamos en la serie terminológica luminosa. La monarquía de los Austria será así asidero al que colgar la noción en la literatura española del Renacimiento. Con un matiz de nuevo fundamental: lo que en López de Yanguas, Castiglione y Garcilaso se mantiene en un espacio estrictamente laico, desacralizado, pagano incluso en las alusiones a Saturno, poco a poco, como sucedía también al símbolo luminoso, va virando hacia otro terreno, el del programa político religioso. Pensemos en un texto como la Jerusalén conquistada de Lope de Vega, escrita en i6og. En el séptimo libro un santo con dones proféticos expone a Alfonso VIII de Castilla sus vaticinios, que comienzan con los Reyes Católicos: "Que de tu sangre el último Fernando / la hermosa doña Juana, que anticipo / a cuantas vio la Edad de Oro reinando / al duque de Austria la dará a Filipo" (Lope de Vega 2003: 270); hasta culminar en Felipe III, el monarca español

\footnotetext{
I3 Tanto en la cuarta égloga: "Solo, casta Lucina, atiende amante / al niño que nos nace, a cuyo influjo, / muerta la edad de hierro, una áurea gente / en todo el mundo va a surgir: Apolo, / tu hermano reina ya (2003: 432; VV. II-I5); como en la Eneida: "Y este varón, ¿lo ves?, ¿el que los dioses / tanto te han prometido, Augusto César? / Casta de un dios, al Lacio el siglo de oro / hará volver, el siglo de Saturno (2OO3: 65I; VV. II4I-II44).
} 
cuando Lope escribe el texto: "corre, tiempo veloz, pasa, camina, / llegue sabio en la paz, fuerte en la guerra, / rayo al hereje vil, cuchillo al moro, / el Tercero Filipe al Siglo de Oro" (p. 27I). La Edad de Oro comienza a perder sus referentes paganos para ganarse el dorado atributo en su lucha contra la herejía y los enemigos de religión.

La misma identificación encontramos en la anónima Relación de las fiestas celebradas en Toledo en I605, con motivo del nacimiento del propio Felipe III. La Edad de Oro es regia y católica, a partir de una interpretación escatológica de la nación: el nuevo tiempo es dorado y luminoso porque el rey pilotará "la nave de la Iglesia militante":

[...]Y tú, niño gigante, pues ya pesa / en tus débiles hombros filipeos, / la nave de la Iglesia militante, / el cetro de dos mundos crece apriesa, / para que oprimas bárbaros tifeos, / y bajes la cerviz del moro Atlante; / armado de diamante, / Godofre sobre el polo de Calisto / te ofrece alegre la famosa espada, / libertad del pirámide de Cristo, / Júpiter español, tu edad dorada / de tantas esperada, / llegue con santa paz de abuelo y padre [...] (Relación...,2000: fol. $37 \mathrm{~V})$.

Merece la pena prestar atención a un matiz que Francisco de Aldana introduce al concepto en las octavas que dedica a Felipe II: “¡OH miserable edad que contrapones / al primer siglo de oro este malino! / Tantos Dionisios das, tantos Nerones, / en vez de un Justiniano, un Constantino" (I997: 4I9; vv. 64I-644). La queja admite su inserción en el cruce de amenazas religiosas a las que el monarca deberá hacer frente. Sin embargo, hay un viraje con respecto a los textos anteriores, algunos de ellos posteriores en el tiempo a éste: Aldana ya no tiene conciencia de estar viviendo en una Edad de Oro, parece como si el esplendor se perdiera, se opacase, como si asomara en estos versos la noción de decadencia que poco a poco invadirá a la sociedad española hasta desembocar en la crisis barroca. Conciencia que aparece cuando, de nuevo, Aldana recurra a la noción de Siglo de Oro, ajena ya a un momento histórico concreto, y referida a la intemporalidad del nacimiento de Cristo: “ $¡ O$ Oh siglo de oro, edad de las edades, / que al Rey nos dio de las eternidades" (Aldana, I997: 323; vv. 55 $5^{\mathrm{I}} 55^{2}$ ).

Dos testimonios del siglo XVII confirman esta sensación de decadencia, de no vivir más en el dorado optimismo filípico, sino en la rudeza del hierro. De Cervantes es el primero, en el parlamento de don Quijote a los cabreros: "Dichosa edad y siglos dichosos aquellos a quien los antiguos pusieron el nombre de dorados, y no porque en ellos el oro, que en esta nuestra edad de hierro tanto se estima, se alcanzase en aquella venturosa sin fatiga alguna" (Cervantes, 2004: I33). Para Don Quijote, la edad dorada no es algo que se esté viviendo o que esté por venir, sino una noción perdida y que él recuerda con nostalgia. Como bien ha señalado Juan Carlos Rodríguez, la referencia al oro se enuncia aquí desde una "ambigüedad cervantina [que] puede resultar filosa", pues el ansia por el oro del que habla Don Quijote alude al "oro que llega de las Indias y que lo domina todo [...] en el interior de ese primer mercado capitalista que lo asfixia todo y por todas 
partes" (Torres Salinas, 2013). En sus palabras trasluce la conciencia de un desencanto que no piensa en un renacimiento de saberes esplendorosos, sino en algo perdido en su turbidez. Opacado el esplendor, sólo queda un presente áspero, la conciencia de una crisis sintetizada por Gracián en el Oráculo manual y arte de prudencia: "Floreció en el siglo de oro la llaneza; en este de hierro, la malicia” (Gracián, 1984: 209). 


\section{Obras citadas}

- Aldana, F. de. (i997). Poesías castellanas completas. (J. Lara Garrido, Ed.). Madrid: Cátedra.

- Altolaguirre, M. (I986). Garcilaso de la Vega. En Obras completas (J. Valender, Ed.) (Vol. II, pp. 9-I49). Madrid: Istmo.

- Arce de Otálora, J. de. (1995). Coloquios de Palatino y Pinciano. (J. L. Ocasar Ariza, Ed.). Madrid: Fundación José Antonio de Castro.

- Auerbach, E. (1975). Mimesis: la representación de la realidad en la literatura occidental. México D.F.: Fondo de Cultura Económica.

- Baron, H. (1993). En busca del humanismo cívico florentino: ensayos sobre el cambio del pensamiento medieval al moderno. México, D.F: Fondo de Cultura Económica.

- Blecua, A. (2006). El concepto de «Siglo de Oro». Signos viejos y nuevos: estudios de historia literaria (pp. $3^{\mathrm{I}-88)}$. Barcelona: Crítica.

- Bouwsma. (200I). Elotoño del Renacimiento. Barcelona: Crítica.

- Cantimori, D. (197I). Storici e storia. Torino: Einaudi.

- Castiglione, B. (2009). El cortesano. (R. Reyes Cano, Ed.). Madrid: Espasa-Calpe.

- Castro, A. (2002). El pensamiento de Cervantes. Obra reunida (Vol. II: Elpensamiento de Cervantes y otros estudios cervantinos, pp. 29-340). Madrid: Trotta.

- Cervantes, Miguel de. (I993). La Galatea. Obras completas (D. Ynduráin, Ed.), (Vol. IV, pp. I-39I). Turner-Biblioteca Castro.

- Cervantes, Miguel de. (2004). Don Quïote de La Mancha. (F. Rico, Ed.). Barcelona: Galaxia Gutenberg.

- Díaz de Toledo, Pero. (I892). Diálogo é razonamiento en la muerte del Marqués de Santillana. En Paz y Mélia, Antonio (Ed.), Opúsculos literarios de los siglos XIV a XVI, Sociedad de Bibliofilos Españoles (pp. 247-362). Madrid: Sociedad de Bibliófilos Españoles.

- Encina, J. del. (I996). Obra completa. (M. A. Pérez Priego, Ed.). Madrid: Turner-Biblioteca Castro. 
- Ferguson, W. K. (1948). The Renaissance in historical thought: five centuries of interpretation. Cambridge: Riverside.

- García Dini, E. (Ed.). (2007). Antología en defensa de la lengua y la literatura españolas. Madrid: Cátedra.

- Garcilaso de la Vega. (2007). Obra poética y textos en prosa. (B. Morros, Ed.). Barcelona: Crítica.

- Gargano, A. (2012). La literatura en tiempos de los Reyes Católicos. Nueva biblioteca románica hispánica. Madrid: Gredos.

- Garin, E. (ı98ı). Edades oscuras y Renacimiento, un problema de límites. La revolución cultural del Renacimiento (pp. 29-7I). Barcelona: Crítica.

- Garin, E. (i98rb). Los cancilleres de la república florentina, de Coluccio Salutati a Bartolomeo Scala. La revolución cultural del Renacimiento (pp. 73-IO5). Barcelona: Crítica.

- Gombrich, E. H. (1984). El Renacimiento y la Edad de Oro. Norma y forma: estudios sobre el arte del Renacimiento (pp. 69-78). Madrid: Alianza Editorial.

- Gómez Moreno, A. (I994). España y la Italia de los humanistas: primeros ecos. Madrid: Gredos.

- Gracián, B. (I984). Oráculo manual y arte de prudencia. El héroe / El discreto; Oráculo manualy arte de prudencia (L. Santa Marina, Ed.) (pp. I39-230). Barcelona: Planeta.

- Herrera, F. de. (200Ia). Anotaciones a la poesía de Garcilaso. (J. M. Reyes e I. Pepe, Eds.). Madrid: Cátedra.

- Keniston, Hayward. (1922). Garcilaso de la Vega. A critical study of his life and Woks. New York: Hispanic Society.

- Lapesa, R. (1985). La trayectoria poética de Garcilaso. Madrid: Istmo.

- Levin, H. (1972). The myth of the Golden Age in the Renaissance. New York: Oxford University Press.

- Lope de Vega. (2003). Jerusalén conquistada. (A. Carreño, Ed.). Madrid: Turner.

- López de Mendoza, Iñigo. (2002). Obras completas: poesía, prosa. (A. Gómez Moreno, Ed.). Madrid: Fundación José Antonio de Castro. 
- López de Yanguas, H. (I967). Farsa de la concordia. Obras dramáticas (F. González Ollé, Ed.) (pp. 75-I26). Madrid: Espasa-Calpe.

- Lucena, Juan de. (I892). Carta exhortatoria a las letras. En Paz y Mélia, Antonio (Ed.), Opúsculos literarios de los siglos XIV a XVI, Sociedad de Bibliofilos Españoles (pp. 2092I7). Madrid: Sociedad de Bibliófilos Españoles.

- Maravall, J. A. (1980). La cultura del barroco: análisis de una estructura histórica. Barcelona: Ariel.

- Maravall, J. A. (I986). Antiguos y modernos: visión de la historia e idea de progreso hasta el Renacimiento. Madrid: Alianza Editorial.

- Maravall, J. A. (i996). El Pre-Renacimiento del siglo XV. En V. García de la Concha (Ed.), Nebrïa y la introducción del Renacimiento en España : actas de la III Academia Literaria Renacentista: Universidad de Salamanca, 9, 10 y 11 de diciembre, 1981 (pp. I7-36). Salamanca: Ediciones Universidad de Salamanca.

- Medina, F. (200I). El maestro Francisco de Medina a sus lectores. En F. de Herrera Anotaciones a la poesía de Garcilaso. (J. M. Reyes e I. Pepe, Eds.) (pp. I87-203). Madrid: Cátedra.

- Mommsen, T. E. (1942). Petrarch’s Conception of the «Dark Ages». Speculum, I7 (2), 226242.

- Morales, Ambrosio de. (195I). Discurso sobre la lengua castellana. En G. Bleiberg (Ed.), Antología de elogios de la lengua española (pp. 43-65). Madrid: Cultura Hispánica.

- Morros, B. C. (Ed.). (2007). Garcilaso de la Vega. Obra poética y textos en prosa. Barcelona: Crítica.

- Navarrete, I. (1997). Los huérfanos de Petrarca: poesía y teoría en la España renacentista. Madrid: Gredos.

- Nebrija, A. de. (I98I). Gramática de la lengua castellana. (A. Quilis, Ed.). Madrid: Editora Nacional.

- Nebrija, A. de. (I989). Vocabulario español-latino (Ed. facs.). Madrid: Real Academia Española.

- Panofsky, E. (1975). Renacimiento y renacimientos en el arte occidental. Madrid: Alianza Editorial.

- Petrarca, F. (1978). Obras. (F. Rico, Ed.). Madrid: Alfaguara. 
- Relación de las fiestas que la imperial ciudad de Toledo hizo al nacimiento del príncipe nuestro señor Felipe III deste nuestro nombre. (2000) (A. Madroñal, Ed.). Real Academia Española: Banco de datos (CORDE). Recuperado a partir de http://corpus.rae.es/cordenet. html

- Rico, F. (1978). Nebrïa frente a los bárbaros: el canon de gramáticos nefastos en las polémicas del humanismo. Salamanca: Universidad de Salamanca, Servicio de Archivos y Bibliotecas.

- Rico, F. (1993). El sueño del humanismo: de Petrarca a Erasmo. Madrid: Alianza Editorial.

- Rico, F. (i996). Lección y herencia de Elio Antonio de Nebrija. En V. García de la Concha (Ed.), Nebrïa y la introducción del Renacimiento en España : actas de la III Academia Literaria Renacentista: Universidad de Salamanca, 9, 10 y 11 de diciembre, 1981. (pp. 9-16). Salamanca: Ediciones Universidad de Salamanca.

- Robles, Juan de. (2007). Primera parte del culto sevillano. En E. García Dini (Ed.), Antología en defensa de la lengua y la literatura españolas (siglos XVI y XVII) (pp. 359-368). Madrid: Cátedra.

- Rodríguez, J. C. (I990). Teoría e historia de la producción ideológica: las primeras literaturas burguesas. Akal Universitaria. Madrid: Akal.

- Rodríguez, J. C. (200I). La literatura del pobre. Granada: Comares.

- Rodríguez, J. C. (2003). El escritor que compró su propio libro: para leer el Quïote. Barcelona: Debate.

- Rodríguez, J. C. (2008). Las formaciones ideológicas del Barroco andaluz. En A. J. Morales (Ed.), Congreso Internacional Andalucía Barroca: actas, Iglesia de San Juan de Dios de Antequera, 17-21 de septiembre de 2007 (Vol. 4 (Ciencia, filosofía y religiosidad), pp. I6I-I70). Sevilla: Consejería de Cultura.

- Salinas, Miguel de. (2007). Rhetórica en lengua castellana. En E. García Dini (Ed.), Antología en defensa de la lengua y la literatura españolas (siglos XVI y XVII) (pp. 359-368). Madrid: Cátedra.

- San Josef, Gerónimo de. (2007). Genio de la historia. En E. García Dini (Ed.), Antología en defensa de la lengua y la literatura españolas (379-386). Madrid: Cátedra.

- Simón Abril, Pedro. (2007). Apuntamientos de cómo se deben reformar las doctrinas y la manera de enseñarlas. En E. García Dini (Ed.), Antología en defensa de la lengua y la litera-

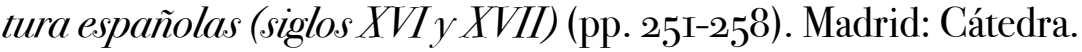


- Soria Ortega, A. (1956). Los humanistas de la corte de Alfonso el Magnánimo. Granada: Universidad de Granada.

- Torres Salinas, Ginés (2OI3). De la luz de Roma al oro de Florencia. Luz y legitimación histórica en los humanistas italianos. Alabe, 7.doi:http://dx.doi.org/Io.I5645/Alabe.2OI3.7.I

- Virgilio. (2003). Obras completas. (A. Espinosa et al., Eds.). Madrid: Cátedra.

-Ynduráin, D. (1994). Humanismo y Renacimiento en España. Madrid: Cátedra. 